\title{
«Bulletin de la Société internationale des amis de Montaigne», 2014-2 et 2015-1, n. 60-61
}

\section{Sabine Lardon}

\section{(2) OpenEdition}

1 Journals

\section{Édition électronique}

URL : http://journals.openedition.org/studifrancesi/4339

DOI : 10.4000/studifrancesi.4339

ISSN : 2421-5856

Éditeur

Rosenberg \& Sellier

\section{Édition imprimée}

Date de publication : 1 septembre 2016

Pagination : 318-319

ISSN : 0039-2944

\section{Référence électronique}

Sabine Lardon, « «Bulletin de la Société internationale des amis de Montaigne», 2014-2 et 2015-1, n. 60-61 », Studi Francesi [En ligne], 179 (LX | II) | 2016, mis en ligne le 01 septembre 2016, consulté le 18 septembre 2020. URL : http://journals.openedition.org/studifrancesi/4339 ; DOI : https://doi.org/ 10.4000/studifrancesi.4339

Ce document a été généré automatiquement le 18 septembre 2020.

\section{(c)}

Studi Francesi è distribuita con Licenza Creative Commons Attribuzione - Non commerciale - Non opere derivate 4.0 Internazionale. 


\title{
«Bulletin de la Société internationale des amis de Montaigne», 2014-2 et 2015-1, n. 60-61
}

\author{
Sabine Lardon
}

\section{RÉFÉRENCE}

«Bulletin de la Société internationale des amis de Montaigne», 2014-2 et 2015-1, n. 60-61, Éditions Classiques Garnier, 142 pp.

1 À l'occasion de la conférence annuelle de la SIAM qui s'est tenue le samedi 18 octobre 2014, Emiliano FERRARI (La philosophie des passions chez Montaigne, p. 13-30) présente son récent ouvrage, Montaigne. Une anthropologie des passions (Paris, Classiques Garnier, 2014). Le fait que Montaigne n'ait jamais écrit un chapitre «Des Passions» montre de manière significative son refus d'aborder la question sous la forme d'un discours théorique ou d'un traité. L'anthropologie montanienne des passions s'appuie sur l'unité indivisible du corps et de l'âme. L'exposé se développe en trois temps: la conception montanienne des rapports entre le corps et l'âme; l'union et l'interaction permanentes entre les deux, qui consacrent l'unité fondamentalement duelle de l'homme; la philosophie morale, enfin, qui découle de cette conception: refusant de diviser l'homme, Montaigne tente à l'inverse de l'embrasser toujours dans sa dualité unifiante ou unité duelle.

2 Travaillant sur les notes manuscrites de l'exemplaire de Bordeaux (EB), Alain LEGROS s'intéresse tout d'abord à l'épigraphe de Montaigne sur le titre-frontispice de l'EB, " Viresque acquirit eundo», pour envisager cette citation de l'Énéide de Virgile (IV, v. 175) comme devise des Essais ("Viresque acquirit eundo». La devise des "Essais" et ses antécédents, pp. 33-40). Dans un second article, il se concentre ensuite sur une addition autographe 
biffée de l'EB qui figure dans le chapitre «Sur des vers de Virgile» du livre III. Après être parvenu à restituer partiellement cette addition éphémère, Alain Legros la commente afin d'en dégager l'idée que se faisait Montaigne de l'évolution de son projet avant de s'intéresser à sa place et aux raisons possibles de sa suppression. Cette étude permet de révéler tout l'intérêt du projet ANR Monloe (dir. Marie-Luce Demonet) qui se propose de transcrire l'intégralité des corrections et additions manuscrites de Montaigne sur l'EB («Ma préface montre que je n'espérais pas tant oser», avait écrit Montaigne, pp. 83-94).

3 Jean-François DUPEYRON (Montaigne anthropologue. Retour sur une idée courante, pp. 41-63) examine, de manière critique, l'idée courante, consacrée par Claude Lévi-Strauss, selon laquelle Montaigne serait le précurseur de l'anthropologie, posant en regard l'hypothèse que la démarche de Montaigne relèverait plus de la désinvolture de l'esprit renaissant que d'une méthode scientifique moderne. Les sources dont il disposait se révèlent douteuses et l'auteur lui-même adopte une attitude nuancée, voire méfiante, à leur égard, leur préférant le témoignage oral de gens grossiers, ayant côtoyé les Indiens, moins susceptibles de fausser les faits que les esprits fins, et sa propre rencontre, invérifiable, avec trois Indiens à Rouen, pour défendre l'idée d'une unité du genre humain et condamner toute atteinte à sa dignité.

Benoît AUTIQUET (Les 'circonstances' et la disparition. Une lecture du chapitre III, 4, des Essais, "De la diversion", pp. 65-81) nous livre une lecture du chapitre «De la diversion» qui part de l'architecture d'ensemble du chapitre pour identifier un passage-clé centré sur la notion de «circonstances» ou «images menues et superficielles». La comparaison des circonstances de la mort dans «De la diversion» avec celles du chapitre "Que philosopher c'est apprendre à mourir» permet d'en dégager les différentes fonctions et d'expliquer, via la notion de "pulsion archéologique» empruntée à G. MathieuCastellani, son intérêt pour Montaigne.

5 Le volume est complété par une conséquente section consacrée aux comptes rendus d'études sur Montaigne, qui reflète l'actualité scientifique et l'évolution des travaux sur l'auteur. 